\title{
Cardiovascular risk prediction models with myocardial perfusion imaging in chronic kidney disease: ACCESSing digits or focusing on the patient?
}

\author{
Dimitri Patriki, MD, a and Andreas A. Giannopoulos, MD, PhD ${ }^{a}$ \\ a Cardiac Imaging, Department of Nuclear Medicine, University Hospital Zurich, Zurich, \\ Switzerland
}

Received Jul 4, 2018; accepted Jul 5, 2018

doi: $10.1007 / \mathrm{s} 12350-018-1367-8$

\section{See related article, pp. 41-50}

Cardiovascular disease (CVD) remains the leading cause for mortality worldwide. ${ }^{1}$ Prevention strategies and the pursuit for predictors of CVD as well as the associated mortality have given rise to several statistical models and algorithms ${ }^{2}$ aiming to predict future events. The multifactorial nature of CVD and the interactions between genetic, social, and environmental risk factors complicate accurate risk assessment. ${ }^{3}$ Commonly, multiparametric prediction models include well known risk factors such as age, gender, smoking, dyslipidemia, hypertension, and diabetes and have been shown to improve our ability for prevention and enhanced screening of patients at risk for cardiovascular events. ${ }^{4-6}$

Nevertheless, in the clinical world such prediction models face several issues that humper its implementation. While the demand for population-adjusted risk scores has increased, the dynamic nature of the disease as well as of the risk factors aggravates the creation of an integrated risk assessment scoring system for all populations. ${ }^{7}$ In addition to the eminent Framingham study $^{4}$ numerous different models have been investigated such as the Europe British/Scottish Regional HeartStudies $^{5}$ or the Munster Cardiovascular Study (PROCAM). ${ }^{6}$ On top of clinical risk factors,

Reprint requests: Andreas A. Giannopoulos, MD, PhD, Cardiac Imaging, Department of Nuclear Medicine, University Hospital Zurich, Ramistrasse 100, $8091 \quad$ Zurich, Switzerland; andreas.giannopoulos@usz.ch

J Nucl Cardiol 2020;27:51-2.

$1071-3581 / \$ 34.00$

Copyright (C) 2018 American Society of Nuclear Cardiology. incorporation of cardiac imaging test results has been shown to possess incremental value for the development of new risk stratification strategies. To that end, nuclear imaging primarily with the stress myocardial perfusion single-photon emission-computed tomography (SPECT) myocardial perfusion imaging $(\mathrm{MPI})^{8}$ represents one of the best investigated modality for risk assessment with regards to myocardial infarction. ${ }^{9-11}$ In addition to sole risk stratification, SPECT-MPI further influences management decisions since patients with moderate to large areas of inducible ischemia are more likely to have a survival benefit from revascularization therapy vs. medical treatment. ${ }^{12}$

In order to develop a risk score for the Japanese population, the J-ACCESS studies-family, that initiated close to 20 years ago, established a database including more than 4000 patients and investigated the prognostic value of ${ }^{99 \mathrm{~m}}$ Tc-tetrofosmin SPECT-MPI in the prognosis of patients with ischemic heart disease. ${ }^{13,14}$ Cardiac event risk estimation was based amongst others on myocardial perfusion defects during stress (using summed stress score), left ventricular ejection fraction (LVEF), age, and presence of diabetes mellitus. Although annual cardiovascular events were significantly lower in Japan compared to those in the USA and Europe, it was shown that cardiovascular event rates were higher in patients with larger perfusion defects and reduced LVEF. ${ }^{14}$ Follow-up studies, such as the JACCESS-3 demonstrated the ability and usefulness of SPECT-MPI to predict 3-year outcomes in patients with chronic kidney disease (CKD), a condition well associated with the risk of death, hospitalization as well as cardiovascular events. $^{15}$

To complement these previous findings, in the current issue of the Journal, Nakajima et al. ${ }^{16}$ investigated the accuracy of three risk models derived from the J-ACCESS study to predict major events in a new cohort 
of 526 patients with CKD. One four- and two fiveparametric models were utilized, with the latter two including information on the stage of CKD (as absolute estimated glomerular filtration rate (eGFR) numbers and as categorical values, respectively). Using the actual 3year outcomes of the J-ACCESS 3 study as a reference, all three risk models were shown to perform well with regards to risk stratification. The authors elegantly demonstrated that the J-ACCESS risk models can correctly stratify CKD patients with eGFR $\geq 15 \mathrm{~mL} / \mathrm{min} /$ $1.73 \mathrm{~m}^{2}$ into low, intermediate, or high risk of developing major cardiac events while patients with end-stage disease $\left(\mathrm{eGFR}<15 \mathrm{~mL} / \mathrm{min} / 1.73 \mathrm{~m}^{2}\right)$ are at high risk, as expected, regardless of estimated risk values. The study focused solely on patients with CKD G-stage 3-5 and notably, the receiver-operating characteristics analysis for cardiac events prediction were rather moderate (with area under the curve values $\sim 0.66$ ) for all three models. Furthermore, although inclusion of eGFR improved risk estimation, all three risk models underestimated the actual outcomes of patients with CKD.

Risk scores are designed to assist physicians in clinical decisions by simplifying perplex relationships. Increased complexity of a score with diverse inclusion and exclusion criteria blunders the purpose of the score itself. This could very well be one of the reasons for the relative underutilisation of risk scores in clinical practice. Nevertheless, the identification and potential future implementation of additional clinical or non-clinical parameters (as for example SPECT-MPI) can enhance the accuracy of risk stratification analysis allowing for improved understanding of CVD and enabling more opportunities for prevention. The study by Nakajima et. al. ${ }^{16}$ represents a further step towards a more accurate prediction of cardiovascular events by combining SPECT-MPI findings and clinical risk factors for the Japanese population.

The quest for the perfect risk score will definitely carry on and the authors have added yet a small stone into building patient-specific risk models. Notwithstanding the relevance of cardiovascular risk assessment it still remains an estimate. An estimate that can facilitate therapeutic decisions but will always contain a level of uncertainty. Risk scores hold great potential with regards to epidemiologic assessment; as physicians treat individuals and not entire populations, novel risk scores are highly valuable, they shall not however replace our clinical evaluation and drift the focus away from the patient.

\section{Disclosure}

The University Hospital Zurich holds a research contract with GE Healthcare.

\section{References}

1. Naghavi M, Wang H, Lozano R, Davis A, Liang X, Zhou M, Vollset SE, Ozgoren AA, Abdalla S, Abd-Allah F, Aziz MI, GBD 2013 mortality and causes of death collaborators. Global, regional, and national age-sex specific all-cause and cause-specific mortality for 240 causes of death, 1990-2013: a systematic analysis for the Global Burden of Disease Study 2013. Lancet. 2015;385:117-71.

2. Wierzbicki AS. New directions in cardiovascular risk assessment: the role of secondary risk stratification markers. Int J Clin Pract. 2012;66:622-30.

3. Cooney MT, Dudina AL, Graham IM. Value and limitations of existing scores for the assessment of cardiovascular risk: a review for clinicians. J Am Coll Cardiol. 2009;54:1209-27.

4. Sheridan S, Pignone M, Mulrow C. Framingham-based tools to calculate the global risk of coronary heart disease. J Gen Intern Med. 2003;18:1039-52.

5. Tunstall-Pedoe H. Cardiovascular risk and risk scores: ASSIGN, Framingham, QRISK and others: how to choose. Heart. 2011;97:442-4.

6. Assmann G, Schulte H, Cullen P, Seedorf U. Assessing risk of myocardial infarction and stroke: new data from the Prospective Cardiovascular Münster (PROCAM) study. Eur J Clin Invest. 2007;37:925-32.

7. Anderson KM, Odell PM, Wilson PW, Kannel WB. Cardiovascular disease risk profiles. Am Heart J. 1991;121:293-8.

8. Klocke FJ, Baird MG, Lorell BH, et al. ACC/AHA/ASNC Guidelines for the Clinical use of cardiac radionuclide imagingexecutive summary: A Report of the American College of Cardiology/American Heart Association Task Force on Practice Guidelines (ACC/AHA/ASNC Committee to Revise the 1995 Guidelines for the Clinical Use of Cardiac Radionuclide Imaging). J Am Coll Cardiol. 2003;42:1318-33.

9. Iskander $\mathrm{S}$, Iskandrian AE. Risk assessment using single-photon emission computed tomographic technetium-99m sestamibi imaging. J Am Coll Cardiol. 1998;32:57-62.

10. Shaw LJ, Hendel R, Borges-Neto S, et al. Prognostic value of normal exercise and adenosine $(99 \mathrm{~m}) \mathrm{Tc}$-tetrofosmin SPECT imaging: results from the multicenter registry of 4,728 patients. $\mathrm{J}$ Nucl Med. 2003;44:134-9.

11. Hachamovitch R, Berman DS, Shaw LJ, et al. Incremental prognostic value of myocardial perfusion single photon emission computed tomography for the prediction of cardiac death: differential stratification for risk of cardiac death and myocardial infarction. Circulation. 1998;97:535-43.

12. Hachamovitch R, Hayes SW, Friedman JD, et al. Comparison of the short-term survival benefit associated with revascularization compared with medical therapy in patients with no prior coronary artery disease undergoing stress myocardial perfusion single photon emission computed tomography. Circulation. 2003;107:2900-7.

13. Kusuoka H. Shigeyuki. Surveillance study for creating the national clinical database related to ECG-gated myocardial perfusion SPECT of ischemic heart disease: J-ACCESS study design. Ann Nucl Med. 2006;20:195-202.

14. Nakajima K, Nishimura T. Prognostic table for predicting major cardiac events based on J-ACCESS investigation. Ann Nucl Med. 2008;22:891-7.

15. Go AS, Chertow GM, Fan D, et al. Chronic kidney disease and the risks of death, cardiovascular events, and hospitalization. N Engl J Med. 2004;351:1296-305.

16. Nakajima K, Nakamura S, Hase H, et al. Risk stratification based on J-ACCESS risk models with myocardial perfusion imaging: risk versus outcome in patients with chronic kidney disease. J Nucl Cardiol. 2018. https://doi.org/10.1007/s12350-018-1330-8. 